\title{
Transformation of percutaneous venoarterial extracorporeal membrane oxygenation access to a safe peripheral arterial cannulation
}

\author{
Stefanos Demertzis, MD, PhD, ${ }^{\mathrm{a}}$ and Thierry Carrel, $\mathrm{MD}, \mathrm{PhD},{ }^{\mathrm{b}}$ Lugano and Bern, Switzerland
}

Venoarterial extracorporeal membrane oxygenation (ECMO) support is an accepted lifesaving approach for cardiogenic shock both in and, more recently, out of the hospital setting. In these circumstances percutaneous cannulation of the groin vessels is frequently used to initiate extracorporeal support and stabilize the patient. Inadequate arterial flow distal to the cannulation site can cause limb ischemia and significant morbidity. ${ }^{1}$ A timely transformation of this percutaneous access to a safe peripheral arterial cannulation could possibly prevent the deleterious effect of distal limb ischemia.

\section{SURGICAL TECHNIQUE}

A curved vertical inguinal incision (leaving the cannula insertion site medially) is preferred. The femoral arteries are prepared for proximal and distal control, and the cannula and its entrance in the femoral artery are visualized (Figure 1, A). Two umbilical tapes are passed around the common femoral artery and secured with tourniquets. The tourniquets are then tightened (Figure 1,B). This maneuver ensures that the segment of the common femoral artery between the tourniquets, which contains the percutaneously inserted cannula, does not have any flow. A longitudinal arteriotomy is made and extended as appropriate to accommodate an end-to-side anastomosis between the vessel and a beveled $8-\mathrm{mm}$ vascular prosthesis. The anastomosis is sewn in the usual manner (continuous suture of 5-0 polypropylene thread with a $\mathrm{C} 1$ needle; Figure $1, C$ ). A new cannula is then introduced into the prosthesis and secured with ligatures. The distal tourniquet is loosen for retrograde de-airing, and the cannula is clamped. The proximal tourniquet is then released, and the prosthesis is perfused. Eventual anastomotic bleeding is thus controlled. The switch from the percutaneous cannula to the transprothetic cannula is accomplished during a short interruption of the ECMO perfusion (usually within

From the Department of Cardiac Surgery, ${ }^{\mathrm{a}}$ Cardiocentro Ticino, Lugano, Switzerland, and University of Bern, Bern, Switzerland; and the Department of Cardiovascular Surgery, ${ }^{\text {b }}$ Inselspital Bern University Hospital and University of Bern, Bern, Switzerland.

Disclosures: Authors have nothing to disclose with regard to commercial support.

Received for publication Feb 26, 2013; revisions received June 16, 2013; accepted for publication June 27, 2013; available ahead of print Aug 19, 2013.

Address for reprints: Stefanos Demertzis, MD, PhD, Cardiocentro Ticino, Via Tesserete 48, 6900 Lugano, Switzerland (E-mail: demertzis@cardiocentro.org).

J Thorac Cardiovasc Surg 2013;146:1293-4

$0022-5223 / \$ 36.00$

Copyright (C) 2013 by The American Association for Thoracic Surgery

http://dx.doi.org/10.1016/j.jtcvs.2013.06.038

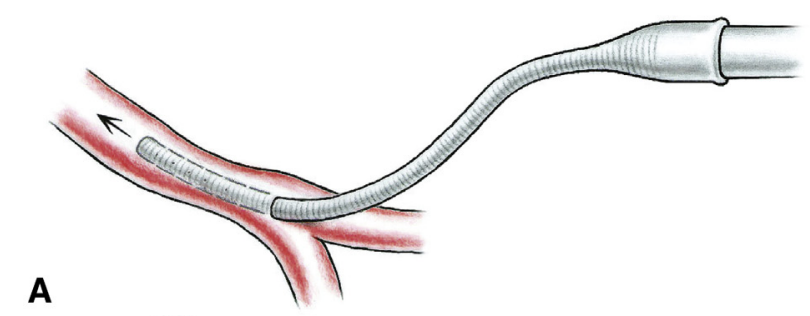

A
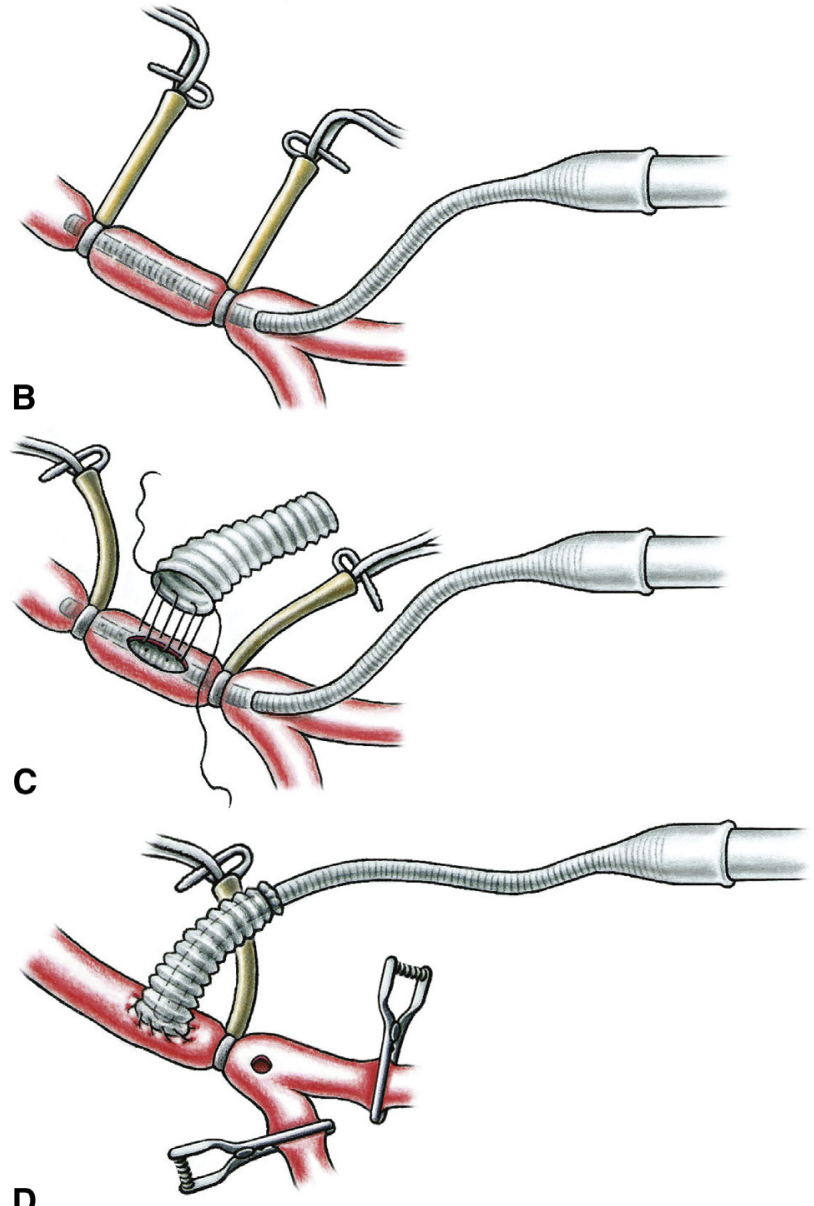

FIGURE 1. The four major steps for transforming a percutaneous cannulation to a safe transprosthetic cannulation. See the text for a detailed description. A, Exposure and visualization; B, tourniquet placement. $\mathrm{C}$, prosthetic anastomosis. D, recannulation through graft.

seconds). The distal tourniquet remains under manual control. The distal femoral vessels are controlled by means of bulldog clamps and the percutaneous cannula is extracted (Figure 1,D). The insertion site can be sutured directly, or the respective femoral artery can be reconstructed with 
appropriate surgical techniques. Depending on the clinical situation and judgment, a Fogarty maneuver can also be performed at this stage, eventually making use of the cannula insertion side. The wound is drained and closed in the usual manner.

\section{RESULTS}

We applied this technique in 3 male patients $(62 \pm 6$ years). Of these, 2 required salvage and 1 urgent preventive venoarterial ECMO support in the catheterization laboratory. All presented with cardiogenic shock due to STsegment elevation myocardial infarction. All underwent percutaneous transluminal coronary angioplasty of the proximal left anterior descending artery or the main stem of the left coronary artery. Perfusion cannulas (18F and 24F) were introduced percutaneously through the already wired groin vessels. Transformation to a transprosthetic cannulation was performed in all cases, either electively at the end of the percutaneous transluminal coronary angioplasty or after disappearance of the peripheral pulses (by Doppler ultrasonography) 8 and 22 hours after initiation of the venoarterial ECMO (urgent transformation). In neither cases were there any clinical signs of manifest tissue ischemia and no thrombotic material was retrieved from the peripheral arterial branches; relief fasciotomy was therefore not performed.

\section{DISCUSSION}

Prevention of distal limb ischemia is a clinical priority after percutaneous institution of venoarterial ECMO. The adequacy of the arterial perfusion distal to the cannulation site can be monitored clinically and by means of Doppler ultrasonography. Adequate arterial perfusion to the distal limb should be established as soon as possible to prevent the deleterious consequences of distal limb ischemia.

Current techniques for distal perfusion after peripheral arterial cannulation $^{2-5}$ consist of the introduction of an additional perfusion catheter in the distal artery. The effective distal perfusion flow can be inadequate, however, because it is determined by the resistance of the stopcock connection of the perfusion catheter to the circuit and of the catheter itself. After decannulation, the artery is left with two openings requiring care. The surgical technique proposed here ensures adequate distal perfusion, prepares a safe decannulation and stenosis-free reconstruction of the artery, and gives the surgeon the chance to reconstruct the insertion hole of the percutaneous cannula or the possibility of performing an embolectomy of the distal femoral arteries under undisturbed ECMO perfusion. This technique should be seen as an enrichment of the armamentarium and lower the threshold for a proactive approach toward prevention of distal limb ischemia in critically ill patients placed on percutaneous venoarterial ECMO.

\section{References}

1. Bisdas T, Beutel G, Warnecke G, Hoeper MM, Kuehn C, Haverich A, et al. Vascular complications in patients undergoing femoral cannulation for extracorporeal membrane oxygenation support. Ann Thorac Surg. 2011;92:626-31.

2. Greason KL, Hemp JR, Maxwell JM, Fetter JE, Moreno-Cabral RJ. Prevention of distal limb ischemia during cardiopulmonary support via femoral cannulation. Ann Thorac Surg. 1995;60:209-10.

3. Huang SC, Yu HY, Ko WJ, Chen YS. Pressure criterion for placement of distal perfusion catheter to prevent limb ischemia during adult extracorporeal life support. J Thorac Cardiovasc Surg. 2004;128:776-7.

4. Madershahian N, Nagib R, Wippermann J, Strauch J, Wahlers T. A simple technique of distal limb perfusion during prolonged femoro-femoral cannulation. J Card Surg. 2006;21:168-9.

5. Russo CF, Cannata A, Vitali E, Lanfranconi M. Prevention of limb ischemia and edema during peripheral venoarterial extracorporeal membrane oxygenation in adults. J Card Surg. 2009;24:185-7.

\section{Correction of pectus excavatum through a minimally invasive approach with subxyphoid incision and 3-point fixation}

\author{
Sheldon J. Bond, MD, and Hirikati S. Nagaraj, MD, Louisville, Ky \\ From the Division of Pediatric Surgery, Department of Surgery, University of \\ Louisville School of Medicine, Louisville, Ky. \\ Disclosures: Authors have nothing to disclose with regard to commercial support. \\ Received for publication March 28, 2013; revisions received May 2, 2013; accepted \\ for publication July 8, 2013; available ahead of print Aug 28, 2013. \\ Address for reprints: Sheldon J. Bond, MD, Division of Pediatric Surgery, Depart- \\ ment of Surgery, University of Louisville School of Medicine, 315 E Broadway \\ St, Suite 565, Louisville, KY 40202 (E-mail: sjbond01@louisville.edu). \\ J Thorac Cardiovasc Surg 2013;146:1294-6 \\ $0022-5223 / \$ 36.00$ \\ Copyright (c) 2013 by The American Association for Thoracic Surgery \\ http://dx.doi.org/10.1016/j.jtcvs.2013.07.014
}

The development of the minimally invasive technique known as the Nuss procedure for pectus excavatum has clearly been a benefit to children with this chest wall deformity. ${ }^{1}$ There have already been several modifications, and certainly additional modifications will be developed as the technique continues to be implemented. Many of these modifications have been developed in response to procedural complications. Cardiac and aortic lacerations have been described after minimally invasive repair of pectus excavatum. ${ }^{2}$ Proposed solutions have included a subxyphoid 